\title{
Infectious diseases prioritisation for event-based surveillance at the European Union level for the 2012 Olympic and Paralympic Games
}

A Economopoulou' ${ }^{1}$, P Kinross (Pete.Kinross@ecdc.europa.eu) ${ }^{1}$, D Domanovic ${ }^{1}$, D Coulombier ${ }^{1}$

1. European Centre for Disease Prevention and Control, (ECDC), Stockholm, Sweden

Citation style for this article:

Economopoulou A, Kinross P, Domanovic D, Coulombier D. Infectious diseases prioritisation for event-based surveillance at the European Union level for the 2012 Olympic and Paralympic Games. Euro Surveill. 2014;19(15):pii=20770. Available online: http://www.eurosurveillance.org/ViewArticle.aspx?Articleld=20770

Article submitted on 19 April 2013 / published on 17 April 2014

In 2012, London hosted the Olympic and Paralympic Games (the Games), with events occurring throughout the United Kingdom (UK) between 27 July and 9 September 2012. Public health surveillance was performed by the Health Protection Agency (HPA). Collaboration between the HPA and the European Centre for Disease Prevention and Control (ECDC) was established for the detection and assessment of significant infectious disease events (SIDEs) occurring outside the UK during the time of the Games. Additionally, ECDC undertook an internal prioritisation exercise to facilitate ECDC's decisions on which SIDEs should have preferentially enhanced monitoring through epidemic intelligence activities for detection and reporting in daily surveillance in the European Union (EU). A team of ECDC experts evaluated potential public health risks to the Games, selecting and prioritising SIDEs for event-based surveillance with regard to their potential for importation to the Games, occurrence during the Games or export to the EU/European Economic Area from the Games. The team opted for a multilevel approach including comprehensive disease selection, development and use of a qualitative matrix scoring system and a Delphi method for disease prioritisation. The experts selected 71 infectious diseases to enter the prioritisation exercise of which 27 were considered as priority for epidemic intelligence activities by ECDC for the EU for the Games.

\section{Introduction}

A mass gathering (MG) has been defined as a gathering of more than 1,000 persons at a specific location for a specific purpose and for a defined duration $[1,2]$. As MGs can represent a burden for public health systems, some preparedness planning should be considered in advance to mitigate the unusual pressures. Adverse health events at MGs are relatively rare, but have been described in the literature $[3,4]$.

In 2012, London hosted the Olympic and Paralympic Games (the Games), with events occurring throughout the United Kingdom (UK) between 27 July and 9
September 2012, with the majority in London and the south of England. The organisers expected approximately nine million spectators and 300,000 participants, including athletes, officials, media and workforce [5-7].

The European Centre for Disease Prevention and Control (ECDC) is mandated to identify, assess and communicate current and emerging risks to human health from communicable diseases [8]. Information regarding infectious and non-infectious events is collected by the epidemic intelligence team at ECDC in a database for event-based surveillance named the Threat Tracking Tool. A dedicated indicator-based surveillance database, The European Surveillance System (TESSy), collects data on mandatorily notifiable diseases sent by Member States of the European Union (EU) and European Economic Area (EEA) under Decision 2119/98/ EC $[9,10]$ : at the time of the Games, this included $27 \mathrm{EU}$ countries plus Norway, Iceland and Liechtenstein.

Public health surveillance in the UK for London 2012 was coordinated by the Health Protection Agency (HPA), now part of Public Health England. Close collaboration between the HPA's international team and ECDC was established for detection and assessment of infectious and non-infectious events occurring worldwide during the Games. ECDC reinforced its event-based surveillance activities to enhance detection and assessment of these events relevant to the Games in a timely manner. For this purpose, keywords for tools such as software that aggregates a specific type of information from multiple online sources (media aggregator) had to be selected, to be used for threat detection. Special attention was paid to infectious disease events that are more common than non-infectious environmental events for a MG setting [11]. As the list of infectious diseases representing a risk for public health is long, financial and human resources limited and adverse health events rare, a priority-setting exercise was deemed necessary to facilitate ECDC's decisions on which infectious diseases should have preferentially 
enhanced detection and monitoring, independently of the criteria set by HPA [12]. Non-infectious environmental events were not prioritised. In the absence of a standard method, prioritisation of infectious diseases for event-based surveillance during each MG is usually achieved empirically [11-15].

We aimed to employ a reproducible, transparent, qualitative method to prioritise infectious diseases occurring worldwide and representing a risk for public health during MGs, in order to develop a list of significant infectious disease events (SIDEs) that would enhance event-based surveillance at ECDC for the Games. The use of two independent approaches, one by ECDC and the other by HPA, for the prioritisation of infectious disease events is likely to have increased the overall sensitivity of event-based surveillance during the Games.

\section{Methods}

A team composed of three ECDC experts (generic expert team) was assigned to evaluate potential public health threats to the Games, as well as to select and prioritise SIDEs for the event-based surveillance system. To this end, the generic expert team opted for a multilevel approach including the selection of infectious diseases for prioritisation, qualitative scoring of diseases using a consensus-building Delphi method and a risk matrix [16-24].

A total of 56 ECDC experts from seven diseases programmes (disease expert teams) participated in the scoring and Delphi method. The disease programmes covered the following topics: food- and waterborne and zoonoses, vaccine-preventable diseases, emerging and vector-borne diseases, tuberculosis, airborne diseases, human immunodeficiency virus (HIV) and other sexually transmitted infections and antimicrobial resistance and healthcare-associated infections.

Selection of infectious diseases for surveillance A list of infectious diseases to consider for prioritisation was compiled using the following criteria: (i) mandatorily notifiable infectious diseases that were reported to TESSy in 2010; (ii) potential infectious threats to Europe that had been identified and monitored in the Threat Tracking Tool in June to September of 2005 to 2011 inclusive, i.e. the months surrounding the 2012 Olympic and Paralympic Games; (iii) events reported in the HPA's weekly epidemiological reports from May to September 2011; (iv) diseases reportable to the World Health Organization according to the International Health Regulations, e.g. poliomyelitis due to wild type poliovirus; and (v) infectious agents with deliberate release potential [25-30].

Supportive information, including disease severity, incubation periods, transmissibility, routes of infection, geographical distribution, seasonality and distribution of vectors, was collated using sources such as clinical manuals and dedicated web pages [31-35]. The supportive information was used by both the generic expert team as well as the disease expert teams as reference material.

\section{Scoring system and Delphi method}

The generic team scored each disease individually for two parameters: public health impact and likelihood of occurrence. The public health impact was scored from one point (lowest impact) to five points (highest impact) by taking into account the following assigned criteria: morbidity, case- fatality rate, potential of sequelae, the existence of disease-specific treatments, the potential to provoke outbreaks and potential media interest.

The score for likelihood of occurrence ranged from one point (least likely) to five points (most likely). The assigned criteria used to score likelihood of occurrence were the incidence, geographical distribution, seasonal trends, mode of transmission and incubation period. Likelihood of occurrence was scored by the generic team according to three categories in the context of the Games: (i) being imported into the Games; (ii) occurring at the Games; and (iii) being exported from the Games to rest of the EU/EEA. 'Occurring at the Games' meant disease transmission during the Games. The disease expert teams were asked to assess only the likelihood of occurrence of diseases for two categories only: those occurring at the Games and being exported from the Games. The disease expert teams received a list of diseases within their field of expertise, the corresponding data from TESSy and the Threat Tracking Tool, a summary of threats monitored in the HPA weekly epidemiological reports and the collated supportive information from the generic expert team. The experts in each disease expert team discussed the scores to be assigned to each disease. Each team was requested to send one response per team to the generic team, indicating the attributed score for the public health impact of each disease within their field of expertise, in the context of the Games at UK and EU/ EEA level.

A qualitative risk matrix was used by the generic team to assign for every disease a public health risk score of low, medium, high or highest by taking into account the scores for the public health impact and likelihood of occurrence (Table 1) [16]. A table with the scoring results attributed by the generic expert team and by the disease expert teams was then compiled. When there was a divergence in the scores of the teams, the scores were revised. A consensus was achieved according to Delphi method, through discussions between the generic team and each disease expert team separately.

Diseases with an overall public health risk score of high or highest, whether for diseases being imported to the Games, occurring at or being exported from the Games were then included in the final priority list. 
TABLE 1

Risk matrix used by generic expert team to calculate public health risks for the 2012 Olympic and Paralympic Games

\begin{tabular}{|c|c|c|c|c|c|c|}
\hline \multirow{3}{*}{\multicolumn{2}{|c|}{$\begin{array}{l}\text { Likelihood of } \\
\text { occurrence }\end{array}$}} & \multicolumn{5}{|c|}{ Public health impact } \\
\hline & & 1 & 2 & 3 & 4 & 5 \\
\hline & & \multicolumn{3}{|c|}{ Lowest impact } & \multicolumn{2}{|c|}{ Highest impact } \\
\hline \multirow{2}{*}{$\begin{array}{l}1 \\
2\end{array}$} & \multirow{3}{*}{$\begin{array}{l}\text { Least } \\
\text { likely }\end{array}$} & Lowest & Low & Medium & Medium & High \\
\hline & & Low & Medium & Medium & Medium & High \\
\hline 3 & & Medium & Medium & Medium & High & High \\
\hline 4 & \multirow{2}{*}{$\begin{array}{l}\text { Most } \\
\text { likely }\end{array}$} & Medium & Medium & High & High & Highest \\
\hline 5 & & Medium & High & High & Highest & Highest \\
\hline
\end{tabular}

For diseases with the highest impact (a score of 5) and least likely occurrence (a score of 1), the public health impact was considered 'high' and for those with the lowest impact (a score of 1) and the most likely occurrence (a score of 5), the public health impact was considered 'medium'. This arose from the assessment that the risk from a disease with the highest impact on public health but least likely occurrence is considered greater than the risk from the disease with the lowest impact but most likely occurrence.

\section{Results}

\section{Selection of diseases for surveillance}

A list of 71 infectious diseases (including infectious agents that could be deliberately released) resulted from the selection of diseases to be included in the prioritisation exercise (Table 2).

In 2010, data in TESSy showed that in the EU/EEA, foodand waterborne diseases were the diseases reported most frequently, followed by sexually transmitted and airborne diseases. Measles, pertussis and infections due to Haemophilus influenzae were the most commonly reported vaccine-preventable diseases. Travelrelated malaria was the predominating vector-borne disease.

According to the 2010 TESSy data for the UK, sexually transmitted diseases predominated, followed by food- and waterborne diseases. With regard to airborne diseases, tuberculosis predominated followed by Legionnaire's disease. The most commonly reported vaccine-preventable disease was meningococcal disease followed by infections due to Haemophilus influenzae. Finally, among vector-borne diseases, reports of imported malaria predominated.

From June to September, between 2005 and 2011, ECDC's Threat Tracking Tool had monitored 435 threats: among those, 128 were due to food- and waterborne diseases and 100 were related to Legionnaire's disease.

From June to September 2011, 371 health events were documented in the HPA weekly epidemiological reports: among those, 71 were mentioned as gastroenteritis.
Scoring system and Delphi method

The scores attributed by the generic expert team and by the disease expert teams differed for some diseases while it was similar for others (Table 2). The main differences in the scoring were for food-and waterborne diseases and antimicrobial resistance and healthcareassociated infections. The likelihood of infections due to food- and waterborne diseases within the UK was scored higher by the disease expert team. The antimicrobial resistance and healthcare-associated infections expert team added seven groups of pathogens for surveillance. They considered that carriage of the more common nosocomial infections was likely, although the likelihood of infection would be very low in nonhospitalised attendees at the Games. These included community-acquired and hospital-acquired meticillinresistant Staphylococcus aureus, vancomycin-resistant enterococci and extended-spectrum beta-lactamaseproducing Enterobacteriaceae.

During consultations, the generic expert team and disease expert teams discussed differences and found consensus scores. The Delphi method resulted in the inclusion of influenza, influenza-like illness and diphtheria, which were not considered relevant in the first round, and also to the modification of the ranking position for some diseases (Table 3).

\section{Compiling list of surveillance priorities}

After the application of the risk matrix and Delphi method, 27 diseases were considered as priorities for epidemic intelligence activities (Table 3). Foodand waterborne accounted for eight: Escherichia coli infections, campylobacteriosis, typhoid fever, salmonellosis, shigellosis, cholera, hepatitis A and viral gastroenteritis (including norovirus, rotavirus and adenovirus). Zoonoses accounted for four: leptospirosis, rabies, anthrax and arenavirus diseases. Four airborne diseases were selected: influenza, Legionnaires' disease, tuberculosis and 'other acute respiratory infections'. Four vaccine-preventable diseases were included - meningococcal disease, measles, pertussis and diphtheria - and three emerging diseases - smallpox, Ebola or Marburg viruses and severe acute respiratory syndrome (SARS). Infections due to invasive group A streptococcal infections and invasive pneumococcal disease were considered as a priority; among sexually transmitted infections, syphilis and HIV infection were included.

\section{Reported events}

From all infectious disease signals detected during the Games, 49 SIDEs were selected by ECDC's epidemiologic intelligence using the priority list (Table 3) and presented to ECDC's 'round table' (a daily expert meeting for monitoring and assessment of threats within ECDC's mandate, identified though epidemic intelligence) as relevant for the Games. Of the 49 SIDEs selected, 11 were reported to HPA by ECDC. 
TABLE 2A

Generic expert and disease expert team scores for public health risk of infectious diseases ( $\mathrm{n}=71$ ) prioritised for epidemic intelligence screening activity for the 2012 Olympic and Paralympic Games by the European Centre for Disease Prevention and Control

\begin{tabular}{|c|c|c|c|c|c|c|}
\hline \multirow{3}{*}{$\begin{array}{l}\text { Disease } \\
\text { category }\end{array}$} & \multirow{3}{*}{ Pathogen/disease/syndrome } & \multicolumn{5}{|c|}{ Overall public health risk of infection/outbreak } \\
\hline & & \multicolumn{3}{|c|}{$\begin{array}{l}\text { Generic expert team's } \\
\text { assessment }\end{array}$} & \multicolumn{2}{|c|}{$\begin{array}{c}\text { Disease expert teams } \\
\text { assessments }\end{array}$} \\
\hline & & $\begin{array}{l}\text { Imported } \\
\text { to the } \\
\text { Games }\end{array}$ & $\begin{array}{l}\text { Occurring } \\
\text { at the } \\
\text { Games }\end{array}$ & $\begin{array}{l}\text { Exported } \\
\text { from the } \\
\text { Games }\end{array}$ & $\begin{array}{l}\text { Occurring } \\
\text { at the } \\
\text { Games }\end{array}$ & $\begin{array}{l}\text { Exported } \\
\text { from the } \\
\text { Games }\end{array}$ \\
\hline \multirow{4}{*}{$\begin{array}{l}\text { Airborne } \\
\text { diseases }\end{array}$} & Avian Influenza $\mathrm{A}\left(\mathrm{H}_{5} \mathrm{~N}_{1}\right)$ in humans & NA3 & NA3 & NA3 & Lowest & Low \\
\hline & Influenza & Medium & Low & Medium & High & Highest \\
\hline & Tuberculosis & High & High & High & High & Medium \\
\hline & Other acute respiratory illness & Low & Low & Medium & Highest & Highest \\
\hline \multirow{20}{*}{$\begin{array}{l}\text { Emerging } \\
\text { and } \\
\text { vector- } \\
\text { borne } \\
\text { diseases }\end{array}$} & Arenavirus diseases (e.g. Lassa, or New world arenaviruses) & High & NA1 & NA1 & Highest & Highest \\
\hline & Chikungunya & Medium & NA1 & NA1 & High & High \\
\hline & Crimean-Congo haemorrhagic fever & Medium & NA1 & NA1 & High & Medium \\
\hline & Dengue & Medium & NA1 & NA1 & High & High \\
\hline & Ebola or Marburg diseases (filoviruses) & High & High & High & Highest & Highest \\
\hline & Hantaviral infections (Old and New world) & Medium & NA1 & NA1 & Low & Low \\
\hline & Invasive group A streptococcal (iGAS) infections & High & High & High & ND & ND \\
\hline & Leishmaniasis/Chagas disease & Medium & NA1 & NA1 & Low & Lowest \\
\hline & Louse-borne typhus & Medium & NA1 & NA1 & Medium & Low \\
\hline & Lyme disease & Medium & NA1 & NA1 & Low & Low \\
\hline & Malaria & Medium & NA1 & NA1 & High & Medium \\
\hline & Pneumonic plague & Medium & Medium & Medium & Highest & Highest \\
\hline & Q-fever & Medium & Medium & Medium & Medium & Low \\
\hline & Rabies & High & $\mathrm{NA}_{4}$ & $\mathrm{NA}_{4}$ & Medium & Medium \\
\hline & Rift Valley fever & Medium & NA1 & NA1 & Low & Low \\
\hline & Severe acute respiratory syndrome (SARS) & High & High & High & Highest & Highest \\
\hline & Smallpox & High & High & High & Highest & Highest \\
\hline & Tick-borne encephalitis & Medium & NA1 & NA1 & Low & Lowest \\
\hline & West Nile fever & Medium & NA1 & NA1 & Medium & Low \\
\hline & Yellow fever & Medium & $N A_{1}$ & NA1 & High & High \\
\hline \multirow{17}{*}{$\begin{array}{l}\text { Food-and } \\
\text { waterborne } \\
\text { diseases }\end{array}$} & Botulism (in food brought by visitors) & Medium & Medium & Medium & High & Medium \\
\hline & Brucellosis & Medium & Medium & Medium & Medium & Low \\
\hline & Campylobacteriosis & High & High & Medium & Medium & Low \\
\hline & Cholera & High & High & Medium & High & High \\
\hline & Cryptosporidiosis & Medium & Medium & Medium & Medium & Low \\
\hline & $\begin{array}{l}\text { Escherichia coli infections (including enterohaemorrhagic } \\
\text { E. coli (EHEC), Shiga toxin-producing E. coli (STEC), } \\
\text { verocytotoxin-producing E. coli (VTEC) }\end{array}$ & Highest & Highest & Highest & High & High \\
\hline & Viral gastroenteritis (including norovirus, rotavirus, adenovirus) & High & High & High & Medium & Medium \\
\hline & Giardiasis & Medium & Medium & Medium & Medium & Low \\
\hline & Hepatitis A & High & High & High & High & High \\
\hline & Hepatitis E & Medium & Medium & Medium & Low & Lowest \\
\hline & Legionellosis & $\mathrm{NA3}$ & High & High & Low & Lowest \\
\hline & Listeriosis & Medium & Medium & Medium & Medium & Low \\
\hline & Salmonellosis & High & High & High & High & Medium \\
\hline & Shigellosis & High & High & High & Medium & Low \\
\hline & Trichinosis & Medium & Medium & Medium & Low & Lowest \\
\hline & Typhoid fever & High & High & High & Medium & Medium \\
\hline & Yersiniosis & Medium & Medium & Medium & Medium & Low \\
\hline
\end{tabular}

NA1: not applicable due to absence of the pathogen, vector or conditions for transmission; NA2: not applicable because persons infected with such pathogens were not likely to visit or participate in the Games; NA3: not applicable because human-to-human disease transmission is either not possible or very limited; NA4: not applicable because of long incubation period; ND, not determined.

Discrepancies in generic expert team and the disease expert team scores were discussed between these groups through the Delphi method to find the consensus. 


\section{TABLE 2B}

Generic expert and disease expert team scores for public health risk of infectious diseases ( $\mathrm{n}=71)$ prioritised for epidemic intelligence screening activity for the 2012 Olympic and Paralympic Games by the European Centre for Disease Prevention and Control

\begin{tabular}{|c|c|c|c|c|c|c|}
\hline \multirow{3}{*}{$\begin{array}{l}\text { Disease } \\
\text { category }\end{array}$} & \multirow{3}{*}{ Pathogen/disease/syndrome } & \multicolumn{5}{|c|}{ Overall public health risk of infection/outbreak } \\
\hline & & \multicolumn{3}{|c|}{$\begin{array}{l}\text { Generic expert team's } \\
\text { assessment }\end{array}$} & \multicolumn{2}{|c|}{$\begin{array}{l}\text { Disease expert teams' } \\
\text { assessments }\end{array}$} \\
\hline & & $\begin{array}{l}\text { Imported } \\
\text { to the } \\
\text { Games }\end{array}$ & $\begin{array}{l}\text { Occurring } \\
\text { at the } \\
\text { Games }\end{array}$ & $\begin{array}{l}\text { Exported } \\
\text { from the } \\
\text { Games }\end{array}$ & $\begin{array}{l}\text { Occurring } \\
\text { at the } \\
\text { Games }\end{array}$ & $\begin{array}{l}\text { Exported } \\
\text { from the } \\
\text { Games }\end{array}$ \\
\hline \multirow{5}{*}{ Zoonoses } & Anthrax & High & High & High & Medium & Low \\
\hline & Echinococcosis & Low & Low & Low & Lowest & Lowest \\
\hline & Leptospirosis & High & High & Medium & Medium & Low \\
\hline & Toxoplasmosis & Low & Low & Low & Lowest & Lowest \\
\hline & Tularaemia & Medium & Medium & Medium & Low & Low \\
\hline \multirow{7}{*}{$\begin{array}{l}\text { Sexually } \\
\text { transmitted } \\
\text { infections }\end{array}$} & Chlamydia infections & Medium & High & Medium & Medium & Medium \\
\hline & Gonorrhoea & Low & Medium & Medium & Medium & Medium \\
\hline & Hepatitis B & Medium & Medium & Medium & Medium & Medium \\
\hline & Hepatitis C & Medium & Medium & Medium & Medium & Medium \\
\hline & Human immunodeficiency virus (HIV) infection & High & High & NA4 & High & NA4 \\
\hline & Lymphogranuloma venereum (LGV) infection & Medium & Medium & Medium & Medium & Medium \\
\hline & Syphilis & High & High & High & High & High \\
\hline \multirow{11}{*}{$\begin{array}{l}\text { Vaccine- } \\
\text { preventable } \\
\text { diseases }\end{array}$} & Diphtheria & Medium & Medium & Medium & Highest & Highest \\
\hline & Invasive Haemophilus influenza & Medium & Medium & Medium & Lowest & Lowest \\
\hline & Measles & High & High & High & Medium & Medium \\
\hline & Invasive meningococcal disease & Highest & Highest & Highest & Highest & Highest \\
\hline & Mumps & Medium & Medium & Medium & Low & Low \\
\hline & Pertussis & Medium & High & Medium & Low & Low \\
\hline & Invasive pneumococcal disease & $\mathrm{NA} 2$ & $\mathrm{NA} 2$ & $\mathrm{NA} 2$ & Lowest & Lowest \\
\hline & Poliomyelitis & Medium & Medium & Medium & Highest & Highest \\
\hline & Rubella & Medium & Medium & Medium & Medium & Medium \\
\hline & Tetanus & Medium & Medium & Medium & Lowest & Lowest \\
\hline & Varicella & Medium & Medium & Medium & Low & Low \\
\hline \multirow{8}{*}{$\begin{array}{l}\text { Antimicrobial } \\
\text { resistance } \\
\text { and } \\
\text { healthcare- } \\
\text { associated } \\
\text { infections }\end{array}$} & $\begin{array}{l}\text { Community-associated meticillin-resistant Staphylococcus aureus } \\
\text { (CA-MRSA) }\end{array}$ & $\mathrm{NA} 2$ & $\mathrm{NA} 2$ & $\mathrm{NA} 2$ & Low & Low \\
\hline & $\begin{array}{l}\text { Healthcare-associated meticillin-resistant Staphylococcus aureus } \\
\text { (HA-MRSA) }\end{array}$ & $\mathrm{NA} 2$ & $\mathrm{NA} 2$ & $\mathrm{NA} 2$ & Low & Low \\
\hline & Vancomycin-resistant enterococci (VRE) & $\mathrm{NA} 2$ & $\mathrm{NA} 2$ & $\mathrm{NA} 2$ & Low & Low \\
\hline & $\begin{array}{l}\text { Extended-spectrum beta-lactamase (ESBL)-producing } \\
\text { Enterobacteriaceae }\end{array}$ & NA2 & $\mathrm{NA} 2$ & $\mathrm{NA} 2$ & Low & Low \\
\hline & Carbapenemase-producing Enterobacteriaceae & $\mathrm{NA} 2$ & $\mathrm{NA} 2$ & $\mathrm{NA} 2$ & Low & Low \\
\hline & $\begin{array}{l}\text { Nosocomial transmission of transmissible spongiform } \\
\text { encephalopathies variant (Creutzfeldt-Jakob disease) }\end{array}$ & NA4 & NA4 & NA4 & NA4 & NA4 \\
\hline & Carbapenem-resistant Pseudomonas aeruginosa & NA2 & $\mathrm{NA} 2$ & NA2 & Low & Low \\
\hline & Healthcare-associated infections (in general) & NA2 & $\mathrm{NA2}$ & $\mathrm{NA2}$ & NA2 & $\mathrm{NA2}$ \\
\hline
\end{tabular}

NA1: not applicable due to absence of the pathogen, vector or conditions for transmission; NA2: not applicable because persons infected with such pathogens were not likely to visit or participate in the Games; NA3: not applicable because human-to-human disease transmission is either not possible or very limited; NA4: not applicable because of long incubation period; ND, not determined.

Discrepancies in generic expert team and the disease expert team scores were discussed between these groups through the Delphi method to find the consensus. 
Highest priorities for epidemic intelligence for the 2012 Olympic and Paralympic Games by the European Centre for Disease Prevention and Control $(n=27)$

\begin{tabular}{|c|c|c|c|c|c|c|}
\hline \multirow[b]{2}{*}{ Pathogen/disease/syndrome } & \multicolumn{2}{|c|}{ Imported to the Games } & \multicolumn{2}{|c|}{ Occurring at the Games } & \multicolumn{2}{|c|}{$\begin{array}{c}\text { Exported from the } \\
\text { Games }\end{array}$} \\
\hline & Risk $^{\mathrm{a}}$ & $\begin{array}{l}\text { Likelihood } \\
\text { / public } \\
\text { health } \\
\text { impact }\end{array}$ & Risk $^{\mathrm{a}}$ & $\begin{array}{l}\text { Likelihood } \\
\text { / public } \\
\text { health } \\
\text { impact }\end{array}$ & Risk $^{\mathrm{a}}$ & $\begin{array}{l}\text { Likelihood } \\
\text { / public } \\
\text { health } \\
\text { impact }\end{array}$ \\
\hline Meningococcal disease & Highest & $5 / 5$ & Highest & $5 / 5$ & Highest & $3 / 5$ \\
\hline $\begin{array}{l}\text { Escherichia coli infections (including enterohaemorrhagic } \\
\text { E. coli (EHEC), Shiga toxin-producing E. coli (STEC), } \\
\text { verocytotoxin-producing E. coli (VTEC) }\end{array}$ & Highest & $5 / 4$ & Highest & $5 / 4$ & Highest & $5 / 4$ \\
\hline Cholera & High & $5 / 3$ & High & $5 / 3$ & Medium & $2 / 3$ \\
\hline Salmonellosis & High & $5 / 2$ & High & $5 / 2$ & High & $5 / 2$ \\
\hline Viral gastroenteritis (including norovirus, rotavirus, adenovirus) & High & $5 / 2$ & High & $5 / 2$ & High & $5 / 2$ \\
\hline Measles & High & $4 / 4$ & High & $4 / 4$ & High & $4 / 4$ \\
\hline Typhoid fever & High & $4 / 4$ & High & $4 / 4$ & High & $4 / 4$ \\
\hline Campylobacteriosis & High & $4 / 3$ & High & $5 / 3$ & Medium & $3 / 3$ \\
\hline Shigellosis & High & $4 / 3$ & High & $4 / 3$ & High & $4 / 3$ \\
\hline Influenza & High & $4 / 2$ & Medium & $2 / 2$ & Medium & $2 / 2$ \\
\hline Other acute respiratory infections & High & $4 / 2$ & Medium & $1 / 2$ & Medium & $2 / 2$ \\
\hline Invasive group A streptococcal (iGAS) infections & High & $3 / 4$ & High & $4 / 4$ & High & $3 / 4$ \\
\hline Leptospirosis & High & $3 / 4$ & High & $3 / 4$ & Medium & $1 / 4$ \\
\hline Syphilis & High & $3 / 4$ & High & $3 / 4$ & High & $3 / 4$ \\
\hline Tuberculosis & High & $3 / 4$ & High & $3 / 4$ & High & $3 / 4$ \\
\hline Hepatitis A & High & $3 / 2$ & High & $4 / 2$ & High & $4 / 2$ \\
\hline Anthrax & High & $2 / 5$ & High & $1 / 5$ & High & $1 / 5$ \\
\hline Human immunodeficiency virus (HIV) infection & High & $2 / 5$ & High & $2 / 5$ & NA4 & NA4 \\
\hline Arenavirus diseases (Lassa, Junin, Machupo, Guanarito, Sabiá) & High & $1 / 5$ & NA1 & $\mathrm{NA} 1$ & NA1 & NA1 \\
\hline Ebola or Marburg viruses (filoviruses) & High & $1 / 5$ & High & $1 / 5$ & High & $1 / 5$ \\
\hline Rabies & High & $1 / 5$ & $\mathrm{NA}_{4}$ & NA4 & NA4 & NA4 \\
\hline Severe acute respiratory syndrome (SARS) & High & $1 / 5$ & High & $1 / 5$ & High & $1 / 5$ \\
\hline Smallpox & High & $1 / 5$ & High & $1 / 5$ & High & $1 / 5$ \\
\hline Diphtheria & Medium & $5 / 5$ & Low & $4 / 5$ & Low & $2 / 5$ \\
\hline Pneumococcal disease & Medium & $2 / 4$ & High & $3 / 4$ & Medium & $1 / 4$ \\
\hline Pertussis & Medium & $2 / 3$ & High & $4 / 3$ & Medium & $2 / 3$ \\
\hline Legionnaires' disease & $\mathrm{NA}_{3}$ & $\mathrm{NA}_{3}$ & High & $4 / 3$ & High & $4 / 3$ \\
\hline
\end{tabular}

NA1: not applicable due to the absence of the pathogen, vector or conditions for transmission; NA2: not applicable because persons infected with such pathogen were unlikely to visit or participate in London 2012; NA3: not applicable because human-to-human disease transmission is either not possible or very limited; NA4: not applicable because of long incubation period.

Risk: the public health risk of infection/outbreak for each pathogen/disease/syndrome, calculated from its likelihood and public health impact scores using the risk matrix (Table 1).

\section{Discussion}

Although epidemiological surveillance during MGs is an important activity of several public health institutions worldwide, few articles provide methodological guidance for event-based surveillance and prioritisation of diseases in this context. Therefore, in preparation for the 2012 Games, we reviewed projects executed for different public health topics but using similar prioritisation methodologies [17-24].

The methodology used to compile a list of SIDEs for the Games was designed to be comprehensive, pragmatic and reproducible. Its representativeness was promoted by considering threats monitored in previous summers in the UK, the EU/EEA and globally. Considering that most events recorded for previous MGs were related to infectious disease outbreaks and very few to environmental hazards, the latter were not included in the prioritisation exercise. The literature confirms that infectious diseases are in fact more common than environmental hazards for the MG setting [11].

The SIDEs that were considered had all already been described in the literature or had been captured by one 
of the aforementioned surveillance systems. Therefore, those that were not recorded in these outputs by definition could not be included in the priority list for monitoring, due to this limitation of our methodology. Undoubtedly, unexpected events should always be considered as a potential eventuality during MGs, e.g. the emergence of a worldwide event such as the SARS outbreak in 2003. Therefore, when ensuring preparedness for MGs, surveillance for the unexpected should always be included, e.g. by including syndromic surveillance or by recording numbers of hospitalisations due to unexplained illness.

There were no surprises regarding the prioritisation results, which were similar to those from other MGs $[2,11]$. Food- and waterborne diseases were considered the most probable to occur followed by airborne. The normal seasonal trend of increased bacterial gastroenteritis during warmer months in the northern hemisphere can explain this ranking. An increase in the number of cholera cases has been reported by infectious disease surveillance systems globally in recent years; the HPA monitored imported cholera in the UK in the summer months of 2011. This fact and possible high media attention contributed to the inclusion of imported cholera among diseases for prioritised surveillance even though it is unlikely that isolated cases of cholera could give rise to outbreaks in the UK or be spread from the UK to other countries. The influenza pandemic of 2009 contributed to influenza's ranking as a high likelihood of occurrence in the context of a summer Olympics and Paralympics, combined with the expected visitors from southern-hemisphere countries during their influenza season, and the possibility of summer outbreaks of influenza in the UK $[36,37]$. Indeed, the HPA's weekly epidemiological reports for summer 2011 included the monitoring of an outbreak of imported influenza $A\left(\mathrm{H}_{1} \mathrm{~N}_{1}\right)$ pdmog virus infections. The high score for meningococcal diseases is also not surprising given their high infectiousness and casefatality rate. The long incubation period of infectious diseases such as HIV infection and tuberculosis (TB) meant that this was not a priority for the Games; however, given that single cases would attract media and public attention, HIV and TB were considered as a priority for surveillance.

The criteria used to define the likelihood of disease occurrence were the incubation period, incidence, geographical distribution, seasonal trends and mode of transmission, i.e. guided by scientific evidence. The independent scoring of the public health impact and the likelihood of occurrence of a disease, and the use of risk matrix as part of the scoring system maximised the achievable objectivity and added credence to the prioritisation method.

Assessment of public health risk, especially in the context of MGs, presents some difficulties. Ranking of the public health impact of an infectious disease - characterised by its frequency, severity of the outcomes and risk of secondary transmission - can be performed in more or less quantitative terms. Public reaction to infectious disease threats cannot be quantified as easily, however, as it is driven by cultural and emotional conditions. Therefore, diseases such as malaria or hantavirus infection - for which secondary transmission was almost impossible and consequently there was no risk of outbreak - were considered for prioritisation because of the media attention that such a disease could had have. However, both aspects must be considered when assessing the public health impact.

The Delphi method assured a high level of consensus and promoted objectivity in disease prioritisation. Assessment by multidisciplinary disease expert teams allowed the prioritisation to benefit from experts' specific knowledge, team work and grouping of similar diseases to obtain more comparable scoring.

Expert opinion inherently carries some degree of subjectivity, and experts were asked to provide a semiqualitative score based on expert judgement and background data. Subjective judgments can be influenced by topical or newsworthy disease trends. The compiled background data, which included descriptors of current trends, were therefore an indispensable tool to reduce subjectivity in the scoring process. Similarly, discussions between the generic team that acquired and collated the data and disease expert teams in a Delphi process ensured that ranking was reconsidered. Although this method demanded time for preparation and committed resources, it strengthens the validity of the prioritisation process.

During the Games, no major SIDEs were detected (data not shown). This may be explained by effectiveness of preparedness measures before the Games, particularly by the UK, aided by an appraisal of the global epidemiological situation.

The priority list of diseases was given to epidemic intelligence tool developers, who, considering HPA criteria [12], ensured that SIDEs keywords were incorporated in different languages into news aggregator and Internet-trawling software used by the epidemic intelligence teams at ECDC for threat detection. There is a scientific prerequisite to have a reliable, transparent and evidence-based method to rely on when setting priorities. To our knowledge, the combination of a risk matrix and Delphi method has not been used yet elsewhere to develop a priority list of diseases for monitoring during MGs. Being completed relatively quickly (one week) with minimal resources (approximately half a working day per expert), this approach provides a scientific tool for a review of diseases when preparing for a MG. Besides its role during these Games, this tool could provide a permanent legacy, as the protocols can be adapted and the methodology repeated with amendments by ECDC or other institutions. 


\section{Acknowledgments}

ECDC experts in disease programmes, for scoring diseases and participating in Delphi process. Health Protection Agency (HPA), Health Protection Services Colindale, for continued sharing of weekly epidemiological bulletins with ECDC for epidemic intelligence purposes.

\section{Conflict of interest}

None declared.

\section{Authors' contributions}

AE and PK: generated study design and methodology; collected data; applied methodology; members of generic team; coordinated Delphi process. DD: writing and editorial contribution to article. DC: initiated study; contributed to study design and methodology; member of generic team. All authors have critically reviewed and approved the final article.

\section{References}

1. World Health Organization (WHO). Special groups of travellers. In: International travel and health. Geneva: WHO; 2010. p. 171-4.

2. World Health Organization (WHO). Communicable disease alert and response for mass gatherings: key considerations, June 2008. Geneva: WHO; 2008. Available from: www.who.int/csr/ Mass_gatherings2.pdf

3. Richter ML, Chersich MF, Scorgie F, Luchters S, Temmerman M, Steen R. Sex work and the 2010 FIFA World Cup: time for public health imperatives to prevail. Global Health. 2010;6:1. http:// dx.doi.org/10.1186/1744-8603-6-1

4. Trachtman H. Escherichia coli $0104: \mathrm{H}_{4}$ outbreak in Germany. $\mathrm{N}$ Engl J Med. 2012;366(8):766; author reply 766-7. http://dx.doi. org/10.1056/NEJMc1200169

5. Barnes W, Smith R. Travel trends, 2010. Newport: Office for National Statistics. [Accessed 9 Sep 2012]. Available from: http://www.ons.gov.uk/ons/rel/ott/travel-trends/2010/traveltrends---2010.pdf

6. Dorset councils. Dorset \& The Olympics 2012 Olympic \& Paralympic Games Sailing Events 2012. Dorchester: Dorset councils. [Accessed 15 Dec 2012]. Available from: https://www. dorsetforyou.com/sailing2012

7. Olympic Delivery Authority (ODA). Transport plan for the London 2012 Olympic and Paralympic Games. 2nd ed. London: ODA; June 2011. Available from: https://www.gov. uk/government/uploads/system/uploads/attachment data/ file/88493/London_2012_Transport_Plan_-_Ch1-5.pdf

8. Regulation (EC) No $851 / 2004$ of the European Parliament and of the Council of 21 April 2004 establishing a European Centre for disease prevention and control. Official Journal of the European Union. Luxembourg: Publications Office of the European Union. 30.4.2004:L 142. Available from: http://www. ecdc.europa.eu/en/aboutus/key\%20documents/0404_kd_ regulation_establishing_ecdc.pdf

9. European Centre for Disease Prevention and Control (ECDC). The European Surveillance System (TESSy). Stockholm: ECDC. [Accessed 25 Nov 2012]. Available from: http://ecdc.europa.eu/ en/activities/surveillance/TESSy/Pages/TESSy.aspx

10. World Health Organization (WHO). A guide to establishing event-based surveillance. Geneva: WHO; 2008. Available from: http://www.wpro.who.int/emerging diseases/documents/ docs/eventbasedsurv.pdf

11. De Lorenzo RA. Mass gathering medicine: a review. Prehosp Disaster Med. 1997;12(1):68-72.

12. Severi E, Heinsbroek E, Watson C, Catchpole M; HPA Olympics Surveillance Work Group. Infectious disease surveillance fo the London 2012 Olympic and Paralympic Games. Euro Surveill. 2012;17(31):pii=20232.

13. Mathews C, van Rensburg A, Schierhout G, Coetzee N, Lombard C), Fehler HG, et al. An assessment of care provided by a public sector STD clinic in Cape Town. Int J STD AIDS. 1998;9(11):68994. http://dx.doi.org/10.1258/0956462981921215

14. Payne L, Arias P, Kreidl P, Ciotti M, Coulombier D. Preparedness activities ahead of the Beijing 2008 Olympic Games--enhancing EU epidemic intelligence. Euro Surveill. 2008;13(32): pii=18947
15. Abubakar I, Gautret P, Brunette GW, Blumberg L, Johnson D, Poumerol G, et al. Global perspectives for prevention of infectious diseases associated with mass gatherings. Lancet Infect Dis. 2012;12(1):66-74. http://dx.doi.org/10.1016/ S1473-3099(11)70246-8

16. European Centre for Disease Prevention and Control (ECDC). Operational guidance on rapid risk assessment methodology. Stockholm: ECDC; 2011. Available from: http://ecdc.europa.eu/ en/publications/Publications/1108_TED_Risk_Assessment_ Methodology Guidance.pdf

17. Sibbald SL, Singer PA, Upshur R, Martin DK. Priority setting: what constitutes success? A conceptual framework for successful priority setting. BMC Health Serv Res. 2009;9:43. http://dx.doi.org/10.1186/1472-6963-9-43

18. Sibbald SL, Gibson JL, Singer PA, Upshur R, Martin DK. Evaluating priority setting success in healthcare: a pilot study. BMC Health Serv Res. 2010;10:131. http://dx.doi. org/10.1186/1472-6963-10-131

19. Krause G; Working Group on Prioritisation at the Robert Koch Institute. Prioritisation of infectious diseases in public health-call for comments. Euro Surveill. 2008;13(40):pii=18996.

20. Gilsdorf A, Krause G. Prioritisation of infectious diseases in public health: feedback on the prioritisation methodology, 15 July 2008 to 15 January 2009. Euro Surveill. 2011;16(18): pii=19861.

21. Michels ME, Evans DE, Blok GA. What is a clinical skill? Searching for order in chaos through a modified Delph process. Med Teach. 2012;34(8):e573-81. http://dx.doi.org/10. 3109/0142159X.2012.669218

22. Linstone HA, Turoff M, editors. The Delphi Method. Techniques and applications. Reading, MA: Addison-Wesley; 1975.

23. Sahal N, Reintjes R, Eltayeb EM, Aro AR. Feasibility of implementing recommendations to improve communicable diseases surveillance--a modified Delphi study. Afr Health Sci. 2011;11 Suppl 1:S93-9. http://dx.doi.org/10.4314/ahs. v11i3.70077

24. Viergever RF, Olifson S, Ghaffar A, Terry RF. A checklist for health research priority setting: nine common themes of good practice. Health Res Policy Syst. 2010;8:36.

25. Reissman DB, Howard J. Responder safety and health: preparing for future disasters. Mt Sinai J Med. 2008;75(2):135 41. http://dx.doi.org/10.1002/msj.20024

26. Lund A, Gutman SJ, Turris SA. Mass gathering medicine: a practical means of enhancing disaster preparedness in Canada. CJEM. 2011;13(4):231-6.

27. European Commission. Commission Decision of 18 December 2007 amending Decision No 2119/98/EC of the European Parliament and of the Council and Decision2000/96/EC as regards communicable diseases listed in those decisions. Official Journal of the European Union. Luxembourg: Publications Office of the European Union. 28.12.2007: L 344. Available from: http://eurlex.europa.eu/LexUriServ/ LexUriServ.do?uri=0J:L:2007:344:0048:0049:EN:PDF

28. World Health Organization (WHO). International Health Regulations (2005). 2nd ed. Geneva: WHO; 2008. Available from: http://whqlibdoc.who.int/ publications/2008/9789241580410_eng.pdf

29. Tegnell A, Van Loock F, Baka A, Wallyn S, Hendriks J, Werner $A$, et al. Development of a matrix to evaluate the threat of biological agents used for bioterrorism. Cell Mol Life Sci. 2006;63(19-20):2223-8. http://dx.doi.org/10.1007/ s00018-006-6310-5

30. Public Health England (PHE). Weekly epidemiological updates archive. London: PHE. [Accessed 13 Jul 2012]. Available from: http://www.hpa.org.uk/web/HPAweb\&HPAwebStandard/ HPAweb_C/1244442494458

31. Heymann DL. Control of communicable diseases manual. 19th ed. Washington, DC: American Public Health Association; 2008.

32. Lashley FR, Durham JD. Emerging infectious diseases: trends and issues. 2nd ed. New York, NY: Springer Publishing Company; 2007.

33. Gorbach SL, Bartlett JG, Blacklow NR. Infectious diseases. 2nd ed. Philadelphia, PA: WB Saunders; 1992.

34. Mandell GL, Bennett JE, Dolin R. Mandell, Douglas, and Bennett's principles and practice of infectious diseases. 7th ed. Philadelphia, PA: Churchill Livingstone Elsevier; 2010.

35. GIDEON. Infectious diseases module. Los Angeles, CA: GIDEON. [Accessed 15 Dec 2012]. Available from: http://www. gideononline.com/infectiousdiseases/

36. Smith S, Smith GE, Olowokure B, Ibbotson S, Foord D, Maguire $\mathrm{H}$, et al. Early spread of the 2009 influenza $A\left(\mathrm{H}_{1} \mathrm{~N}_{1}\right)$ pandemic in the United Kingdom - use of local syndromic data, MayAugust 2009. Euro Surveill. 2011;16(3):pii=19771.

37. Botelho-Nevers E, Gautret P. Outbreaks associated to large open air festivals, including music festivals, 1980 to 2012. Euro Surveill. 2013;18(11):pii=20426. 